\title{
Why Do People Demand Rent Control?
}

\author{
Daniel Müller (P) Elisabeth Gsottbauer*
}

July 4, 2021

\begin{abstract}
We conduct a representative survey experiment in Germany to understand why people support inefficient policies. In particular, we measure beliefs about and preferences for rent control - a policy that is widely regarded as harmful by experts. To tease out causal mechanisms, we provide randomly selected subsets of participants with empirical estimates about the effects of rent control on rent prices and housing supply and with information about the consensus among economists against rent control. We find that people update their beliefs and that this leads to lower demand for rent control. Left-wingers update their beliefs more strongly, which reduces the ideological gap in support for rent control by about one-third. Providing information about economists' rejection of this policy leads to the largest reduction in support. However, the main drivers of support for rent control are fairness considerations and profit motives. Our study also highlights the importance of trust in expert advice since treatment effects are consistently larger among those who indicate trust in expert advice. Finally, an obfuscated follow-up survey conducted three weeks later reveals that the effects, both on support for rent control and on beliefs, persist only for those who trust.

Keywords: beliefs, demand for bad policies, housing supply, rent control, survey experiment, trust in experts.

JEL classification: H10, H30, H31.
\end{abstract}

*Müller: University of Munich, e-mail: daniel.mueller@econ.lmu.de. Gsottbauer: University of Innsbruck, e-mail: elisabeth.gsottbauer@uibk.ac.at. We benefited from discussions with Audinga Baltrunaite, Antoine Ferey, Heiner Schumacher and Francis Wong. We gratefully acknowledge generous financial support from the SFB F63 at the University of Innsbruck and the Center for Economic Studies at the University of Munich. The order of authors was randomly determined by the Universe Splitter app. 


\section{Introduction}

Economists have long understood the economic costs of price controls theoretically (Friedman and Stigler, 1946, e.g.) and empirically (Glaeser and Luttmer, 2003 , Davis and Kilian, 2011). Consequently, they overwhelmingly oppose price controls in general and rent control in particular 1 Regardless, rent control policies (i.e. the practice of limiting the price a landlord may charge) experience great support among the general public, which is not only evident in survey data but also from the fact that rent control policies are frequently implemented in practice ${ }^{2}$ It is important to understand why this is so, not only because housing markets are economically significant but also because answers to this question might also help understand differences in opinions of the general public and economists in other areas (e.g. carbon taxation). One answer to this puzzle might be that economists and the general public hold different beliefs about the effects of economic policies. Indeed, surveys indicate that the public's opinions about economics often differ greatly from those of economists (Caplan, 2002; Jacob, Christandl, and Fetchenhauer, 2011; Sapienza and Zingales, 2013). Other reasons might be that people do not trust expert advice or that they make different equity-efficiency trade-offs.

In this paper, we aim to understand the disconnect between the opinion held by economic experts and the public in the domain of economic policy. To do so, we conduct a survey experiment among a representative sample of the German population, in which we (i) elicit beliefs about effects of rent control on rental housing supply and rent prices, (ii) measure demand for rent control and (iii) investigate whether beliefs about the workings of such a policy causally affect its support, and (iv) examine whether people follow expert advice. In particular, we compare demand for rent control in a control group to demand in three different treatment groups. The first treatment group, the quantity treatment, is provided with empirical estimates from Diamond, McQuade, and Qian (2019), who show that a rent control regulation in San Francisco reduced the supply of rental housing by

\footnotetext{
1 "IGM Expert Panel" at the University of Chicago: www.igmchicago.org/surveys/rent-control/.

${ }^{2}$ For instance, survey results from the "German Internet Panel' (Wave 14, from 2015)', a representative online panel from the German population based at the University of Mannheim, show that $81 \%$ of 3,500 participants find rent control in Germany "rather good", "good" or "very good". Only $8 \%$ oppose such a regulation. Similar results are found in the US and the UK. The results from our survey among Germans show that the median support for rent control is a 7 on a 1-10 scale.
} 
about $15 \%$. In the second treatment, the price treatment, participants are informed that this policy "likely drove up market rents in the long-run". Both treatments thus provide information about the economic effects of rent control on housing supply and rents. The third treatment, the expert treatment, informs participants about the consensus among economists against rent control, exploiting a poll among leading economists.

In our survey, we elicit beliefs about quantity and price effects of rent control before and after treatment. This approach not only allows us to measure individual belief-updating, but also puts us in a position to estimate the causal effect of beliefs on preferences. In addition, we elicit trust in the information provided to them and we ask respondents about the perceived fairness of rent control and whether they would profit financially from them. Our data thus allow us to examine the importance of trust in expert advice and to disentangle the effects of (potentially mis-calibrated) beliefs from fairness concerns and selfish profit motives as drivers of support.

The take home message of the current paper is that people hold systematically miscalibrated beliefs about the consequences of rent control and that correcting them changes demand for this policy. The same holds true when providing participants with expert recommendations against rent control. In more detail, the experiment delivers the following insights. First, we find that people hold too optimistic views about the consequences of rent control. The quantity treatment leads participants to expect larger reductions in supply and the price treatment causes participants to expect higher rents as compared to the control group. Second, both treatments lower support for rent control policies. This conclusion is not only evident in stated support but also in a revealed preference measure (an actual donation decision between two lobby groups). Third, respondents in the expert treatment lower their support for rent control, too. The effect size is about twice as large as that of the first two treatments. Fourth, important determinants of support for rent control are fairness concerns and financial motives. Fifth, left-wingers are initially more optimistic about the effects of this policy and consequently update beliefs about supplyside reactions more strongly. As a result, the treatment cuts the left-right gap in support for rent control by about one-third. Sixth, our data highlight the crucial role that trust in expert advice plays. Throughout, we consistently find that treatment effects are stronger for those who put more trust in the information provided to them. Also, an obfuscated 
follow-up survey conducted three weeks later reveals that the treatment effects persist only for those who trusted the information.

Our paper relates to several strands of literature. First, several papers have documented that voters suffer from systematic biases in decision-making, leading to poor policy choices. For instance, Kallbekken, Kroll, and Cherry (2011) find evidence for an aversion to implementing Pigouvian taxes in a laboratory experiment, even though this tax increases individual and social welfare. Sausgruber and Tyran (2005) investigate fiscal illusion of voters. In their experiment voters prefer higher indirect- over lower direct taxes although this decreases their profit. Moreover, Sausgruber and Tyran (2011) experimentally show that people prefer taxing others over taxing themselves, resulting in an income loss of up to 20\%. Finally, Dal Bó, Dal Bó, and Eyster (2018) show that people might not anticipate equilibrium effects of new policies, leading to a demand for inefficient policies. An under-appreciation of equilibrium effects could also lead to a demand for rent control since people might not fully factor in the supply-side reactions (i.e. lower supply of housing). Second, we also relate to work that studies how beliefs of economists and the general public differ. For instance, Caplan (2002) finds that economists and the general public systematically disagree and hold different beliefs about economics issues. Further empirical evidence comes from Haferkamp et al. (2009) and Sapienza and Zingales (2013). Finally, our work relates to research that aims to understand how people reason about economic policies and taxes. For instance, Stantcheva (2020) provides comprehensive evidence in the areas of income and estate taxation. Related to the case of rent control is Brandts, Busom, Lopez-Mayán, and Panadés (2019), who use a "refutation text" to influence support for rent control. They find that the text successfully shifts beliefs of undergraduate students about the usefulness of rent control in the direction of the beliefs of economic experts $3^{3}$

\section{Experimental Design and Data}

Overview and Sample. The survey experiment is administered in a sample of the German population exploiting the infrastructure provided by a professional survey company.

\footnotetext{
${ }^{3} \mathrm{An}$ important difference to our study is the fact that the refutation text does not provide factual information about rent control. Instead, the text is designed to encourage critical thinking in students. The authors also do not measure beliefs about the effects of rent control.
} 
By construction, the sample is representative along age, income and gender. The main study and a smaller follow-up study were conducted in May 2021. In total, 4,034 respondents participated in the main survey (we pre-registered 4,000) 4 The main survey includes two attention checks (Haaland, Roth, and Wohlfart, 2021) .5 $^{5}$ As pre-registered, we drop those participants who do not pass the attention checks. We recruited $50 \%$ of the originally surveyed respondents, who had also passed the attention check of the main survey for the follow-up study.

Prior beliefs. After a short introduction, we elicit participants' baseline priors about the effects of rent control policies on supplied housing quantities and rents. In two steps we ask all participants if they think rent control affects the supply of rental housing. In the first step, participants are asked whether they believe in an increase, decrease or no change in the supply of rental housing, as compared to a situation without rent control. Participants who indicate a decrease or an increase in the supplied quantity have the opportunity to further specify their answer with the help of a slider (in percentage changes). We choose this design to ensure that respondents do not confound positive and negative percentage changes. We elicit beliefs about the impact of rent control on the level of rents on a seven-point scale ranging from "much higher" to "much lower" rent prices. We opt for this qualitative scale because the study by Diamond et al. (2019) does not provide numerical estimates of price effects.

Information treatments. Participants are then randomized into three different information treatments and one control group. The first treatment group (quantity) receives information from the study by Diamond, McQuade, and Qian (2019), which shows that "the supply of rental housing decreased by 15 percent" in San Francisco due to the introduction of rent control. The second treatment group (price) receives information about the finding from the same study, namely that rent control "likely drove up market rents in the

\footnotetext{
${ }^{4}$ We pre-registered the experimental survey, sample size and our empirical approach at Aspredicted (No. 64761). Figure 8 in the Appendix summarizes the survey design. Description of the variables and coding of responses is summarized in Section 6.3. Instructions, screenshots and the description of the follow-up study are provided in a Supplementary File.

${ }^{5}$ The first one, immediately after the introduction, asks the participant in an open-ended question to indicate "brown" in response to the question about her favorite color. The second one is located after the information intervention and asks the participant about the topic of the information intervention in a multiple choice question.
} 
long run". The third treatment group (expert) receives information about the consensus among economists against rent control. Specifically, we report poll results from the IGM Economic Expert Panel indicating that "more than $80 \%$ of participating economists oppose rent control due to predominantly negative effects on the housing market, which harms tenants and landlords in the long run". Finally, participants in the control group receive information about an unrelated economic study concerning the economic consequences of Brexit. We opted for an "active" control group to keep the length of the survey constant for all respondents. The information presented to all four groups was intentionally kept as concise as possible.

Socio-demographics. Next, we include questions on participants' socioeconomic background such as age, gender, income, education, household size, employment status and place of residence and we also assess participants' housing situation. These questions also create a break between the information treatment and elicitation of the posterior beliefs.

Posterior beliefs. In this block, we again elicit price and quantity beliefs using the same type of questions as before.

Support for rent control. Next, we ask all respondents for their attitudes towards rent control on a 10-point scale from (1) "very strongly oppose" to (10) "very strongly support". Our secondary measure of support is the decision to donate 100 euros to either a pro- or an anti-rent control lobby group (note that this question was asked at the very end of the survey). Participants could donate only the full amount. Not donating was not an option. We then (truthfully) told participants that we will randomly select one respondent and donate the amount of 100 euros according to the decision made by that participant.

Other attitudes. We measure several other attitudes including support for price controls in general, left-right economic ideology and support for free markets. Moreover, we assess fairness perceptions (of rent control) and respondents' profit motives (whether they would financially profit from rent control). We also elicit efficiency concerns (whether they think people stay in their apartments longer and whether they think there is inefficient matching in the rental housing market due to rent control) and concerns about rent prices (whether they think that rent prices are a problem). Finally, we assess trust in the economic study provided in the information treatment on a 5-point scale, ranging from low to high trust. 


\section{Beliefs About Rent Control}

A first important question to ask about our data is what beliefs people hold about the quantity and price effects of rent control and whether participants update these beliefs in response to the treatments. To answer these questions, Figure 1 displays priors and posteriors about supply (left-hand panel) and price reactions (right-hand panel) for each treatment. The first thing to notice is that, on average, prior beliefs about the quantity reactions are negative and around -8.5 percentage points and that priors about price reactions are close to the expectation that rent control does not change rents. Next, we find evidence that participants in the quantity treatment downward-adjust their posterior beliefs about supply reactions and participants in the price treatment upward-adjust their posteriors about price reactions, suggesting that in this experiment both treatments induced more pessimism about the workings of this policy.
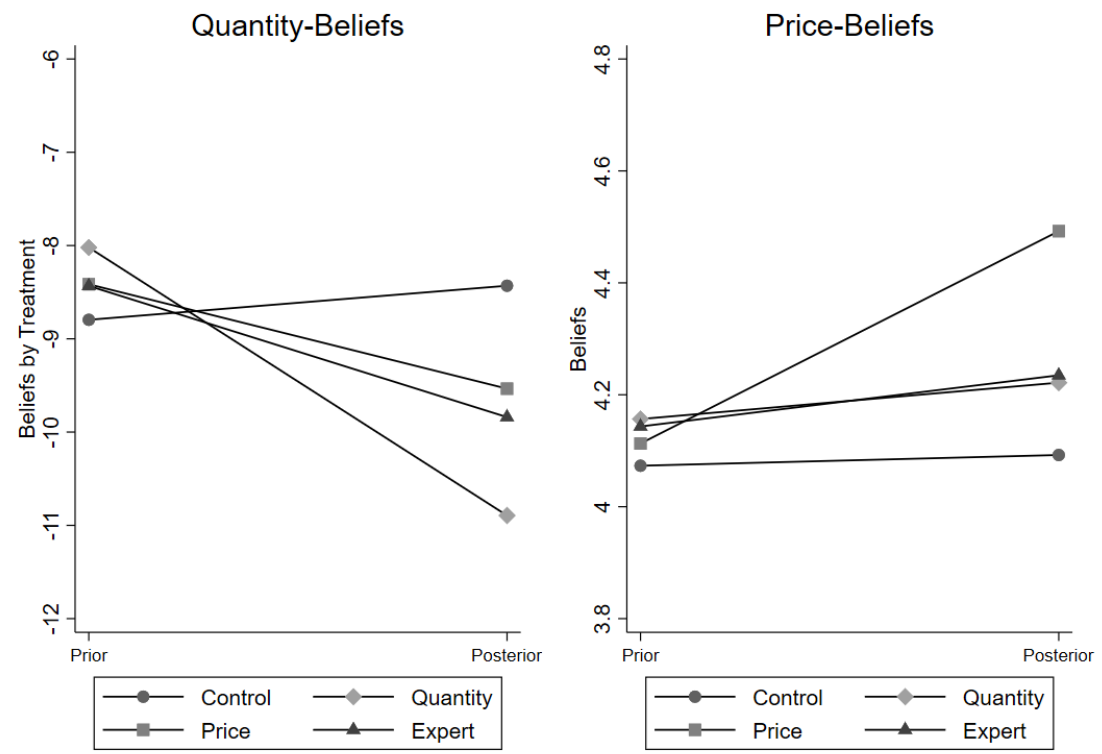

Figure 1: Belief updating about supply- (left panel) and price reactions (right panel) by treatment. Supply change is measured in percent (negative values imply a decrease in supply) and price change on a scale from 1-7 where 7 means "much higher rents", 1 means "much lower rents" and 4 means "no change". 
Table 1 reports results from linear regressions, in which belief updating - the individual difference between the posterior and the prior - is regressed on the treatment dummies and controls ${ }^{6}$ Columns (1) to (6) use updating with regard to quantity effects and columns (7) and (8) use updating with regard to price effects of rent control as dependent variable. The results confirm that the aforementioned findings are statistically significant. That is, participants in the quantity treatment downward-adjust their posteriors by about 3.5 percentage points and participants in the price treatment upward-adjust their posteriors by about 0.4 points on a 1-7 scale relative to the control group. Next, it is insightful to run the quantity-belief updating regressions separately only for those who hold priors above - columns (3) and (4) - and below - columns (5) and (6) - minus 15\%. It turns out that only the former group engages in negative updating ( -6.4 and -8.7 , respectively), the latter group conducts positive updating (around 2-3 percentage points, but not significantly so in column 5). This finding indicates that the average treatment effects mask important individual-level heterogeneity in the sense that the treatment leads some people to upward-adjust their (previously very negative) priors, partly counteracting the effect of the treatment on the average updating: $:^{7}$ Table 1 also shows that updating is stronger for participants who put high trust in the study (compare column (3) with (4) and column (5) with (6)). Again, this finding highlights the importance of trust in the context of expert communication.

It is also noteworthy that there is some updating about quantity reactions in the priceand the expert treatment, relative to the control treatment. Although this effect is not always statistically significant and is weaker than the effect of the quantity treatment, it does suggest a form of cross-learning: participants seem to use the information provided in those two treatments to re-consider their beliefs about supply-side reactions. In particular, it seems reasonable that participants in the expert treatment wonder why experts are against rent control and then conclude that the effects on housing supply are more negative than they previously thought.

\footnotetext{
${ }^{6}$ The set of controls is the same throughout the paper and consists of a dummy that indicates German nationality, a gender dummy, a dummy that is equal to 1 if the respondent works in a full time job, the income, the highest educational level attained, and state-fixed effects. "High trust" is defined here as 4 or 5 on a $1-5$ scale when asked whether they would trust the study.

${ }^{7}$ Figure 4 in the Appendix highlights this point visually.
} 
Finally, Table 3 in the Appendix displays results from regressions, in which the confidence in both the quantity and the price posterior are regressed on the treatment dummies (and controls). It turns out that participants in the quantity treatment indicate higher confidence in their posterior beliefs than do those in the control group. This finding does not hold for the price treatment. 


\begin{tabular}{|c|c|c|c|c|c|c|c|c|}
\hline \multirow{2}{*}{$\begin{array}{l}\text { Belief } \\
\text { Updating }\end{array}$} & \multicolumn{6}{|c|}{ Quantity } & \multicolumn{2}{|c|}{ Price } \\
\hline & (1) & (2) & (3) & (4) & (5) & (6) & (7) & (8) \\
\hline Quantity & $\begin{array}{c}-3.478^{* * *} \\
(0.93)\end{array}$ & $\begin{array}{c}-3.047^{* * *} \\
(1.12)\end{array}$ & $\begin{array}{c}-6.362^{* * *} \\
(1.05)\end{array}$ & $\begin{array}{c}-8.699^{* * *} \\
(1.43)\end{array}$ & $\begin{array}{l}2.252 \\
(1.65)\end{array}$ & $\begin{array}{c}3.399^{* *} \\
(1.65)\end{array}$ & $\begin{array}{l}0.044 \\
(0.05)\end{array}$ & $\begin{array}{l}0.064 \\
(0.05)\end{array}$ \\
\hline Price & $\begin{array}{c}-1.578^{*} \\
(0.84)\end{array}$ & $\begin{array}{l}-1.091 \\
(1.00)\end{array}$ & $\begin{array}{c}-2.038^{* *} \\
(0.96)\end{array}$ & $\begin{array}{c}-2.353^{*} \\
(1.28)\end{array}$ & $\begin{array}{l}-0.333 \\
(1.52)\end{array}$ & $\begin{array}{l}0.566 \\
(1.64)\end{array}$ & $\begin{array}{c}0.367^{* * *} \\
(0.05)\end{array}$ & $\begin{array}{c}0.465^{* * *} \\
(0.06)\end{array}$ \\
\hline Expert & $\begin{array}{c}-2.670^{* * *} \\
(0.87)\end{array}$ & $\begin{array}{c}-2.737^{* * *} \\
(1.00)\end{array}$ & $\begin{array}{c}-2.427^{* *} \\
(0.98)\end{array}$ & $\begin{array}{c}-3.329^{* * *} \\
(1.28)\end{array}$ & $\begin{array}{l}-2.532 \\
(1.63)\end{array}$ & $\begin{array}{c}-2.449 \\
(1.66)\end{array}$ & $\begin{array}{l}0.071 \\
(0.04)\end{array}$ & $\begin{array}{c}0.100^{* *} \\
(0.05)\end{array}$ \\
\hline Constant & $\begin{array}{l}-0.074 \\
(2.14)\end{array}$ & $\begin{array}{l}-0.629 \\
(2.89)\end{array}$ & $\begin{array}{c}-5.263^{* *} \\
(2.43)\end{array}$ & $\begin{array}{c}-6.108^{*} \\
(3.30)\end{array}$ & $\begin{array}{l}4.444 \\
(3.66)\end{array}$ & $\begin{array}{l}5.599 \\
(4.62)\end{array}$ & $\begin{array}{l}0.028 \\
(0.13)\end{array}$ & $\begin{array}{l}-0.053 \\
(0.15)\end{array}$ \\
\hline High trust only & No & Yes & No & Yes & No & Yes & No & Yes \\
\hline Restrictions Prior & No & No & $>-15$ & $>-15$ & $<-15$ & $<-15$ & No & No \\
\hline Controls & Yes & Yes & Yes & Yes & Yes & Yes & Yes & Yes \\
\hline Observations & 3,031 & 1,768 & 1,938 & 1,043 & 1,033 & 686 & 3,031 & 1,768 \\
\hline$R^{2}$ & 0.008 & 0.014 & 0.030 & 0.052 & 0.022 & 0.040 & 0.025 & 0.041 \\
\hline
\end{tabular}

Table 1: OLS regressions with posterior minus prior as dependent variable. Heteroscedasticityrobust standard errors in brackets below. *, **, *** indicate significance at the $10 \%, 5 \%$ and $1 \%$ level, respectively. Quantity, Price and Expert are treatment indicators. Includes only participants that passed the attention checks. Controls are dummies indicating German nationality, gender, full time workers as well as income, education and state-fixed effects. High trust indicates self-reported high trust in the information treatments. 


\section{Support for Rent Control}

\subsection{Main Results}

We now turn to the main research question of this paper: what determines support for rent control? Our data puts us in a position to study the correlation between beliefs and support (via the priors) as well as the causal effect (via the information treatments). First, Figure 2 delivers three insights: (i) overall support for rent control is large (7 on a 1-10 scale in the control group); (ii) all three treatments significantly reduce support relative to the control group (both stated and revealed support); and (iii) the expert treatment displays the largest effect size.
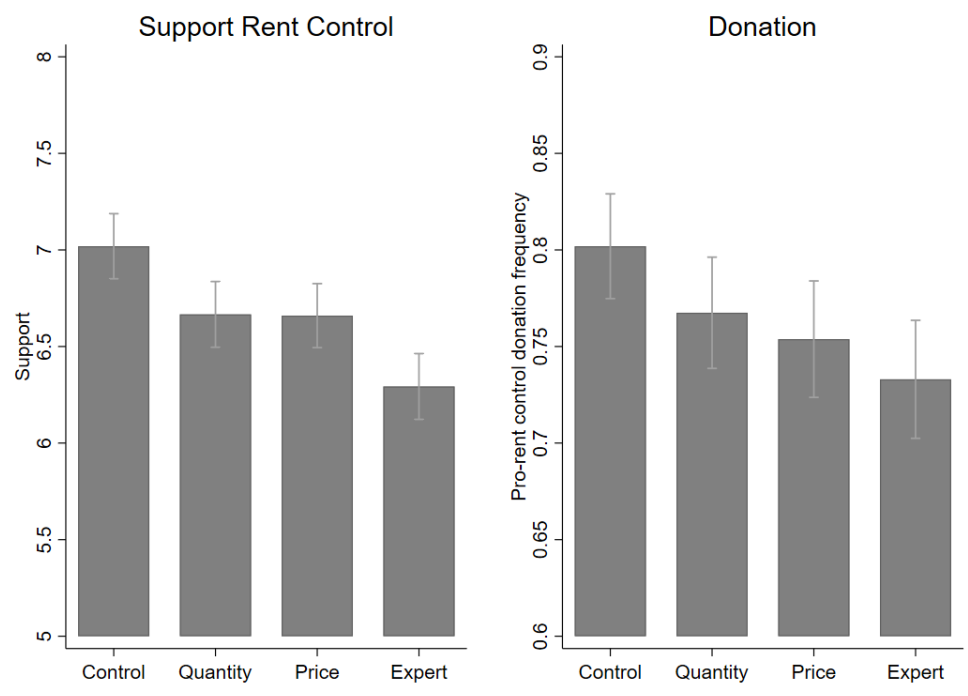

Figure 2: Support rent control (left-hand panel, 1-10 scale) and frequency of donation to pro-rent control initiative (right-hand panel) by treatment. Whiskers indicate $95 \%$ confidence intervals.

Table 2 displays results from regressions, in which stated - columns (1) and (2) - and revealed - columns (3) and (4) - support serve as dependent variables. The treatment dummies, fairness concerns, profit expectations, political ideology, a dummy indicating whether a participant rents out, the perceptions of rents as well as our standard set of controls constitute the independent variables. The table again confirms the main conclusions from above: all three treatments decrease support for rent control. Thus, beliefs play 


\begin{tabular}{|c|c|c|c|c|}
\hline & \multicolumn{2}{|c|}{ Support Rent Control } & \multicolumn{2}{|c|}{ Donation } \\
\hline & (1) & $(2)$ & (3) & $(4)$ \\
\hline Quantity & $\begin{array}{c}-0.201^{* *} \\
(0.09)\end{array}$ & $\begin{array}{c}-0.341^{* * *} \\
(0.11)\end{array}$ & $\begin{array}{l}0.004 \\
(0.02)\end{array}$ & $\begin{array}{c}-0.041^{*} \\
(0.02)\end{array}$ \\
\hline Price & $\begin{array}{c}-0.256^{* * *} \\
(0.09)\end{array}$ & $\begin{array}{c}-0.373^{* * *} \\
(0.12)\end{array}$ & $\begin{array}{l}-0.015 \\
(0.02)\end{array}$ & $\begin{array}{c}-0.045^{*} \\
(0.03)\end{array}$ \\
\hline Expert & $\begin{array}{c}-0.556^{* * *} \\
(0.09)\end{array}$ & $\begin{array}{c}-0.804^{* * *} \\
(0.11)\end{array}$ & $\begin{array}{c}-0.035^{*} \\
(0.02)\end{array}$ & $\begin{array}{c}-0.093^{* * *} \\
(0.03)\end{array}$ \\
\hline Fairness & $\begin{array}{c}1.278^{* * *} \\
(0.05)\end{array}$ & $\begin{array}{c}1.378^{* * *} \\
(0.07)\end{array}$ & $\begin{array}{c}0.132^{* * *} \\
(0.01)\end{array}$ & $\begin{array}{c}0.140^{* * *} \\
(0.01)\end{array}$ \\
\hline Profit & $\begin{array}{c}0.231^{* * *} \\
(0.02)\end{array}$ & $\begin{array}{c}0.229^{* * *} \\
(0.03)\end{array}$ & $\begin{array}{c}0.013^{* * *} \\
(0.00)\end{array}$ & $\begin{array}{c}0.014^{* *} \\
(0.01)\end{array}$ \\
\hline Landlord & $\begin{array}{c}-0.662^{* * *} \\
(0.12)\end{array}$ & $\begin{array}{c}-0.597^{* * *} \\
(0.14)\end{array}$ & $\begin{array}{c}-0.096^{* * *} \\
(0.03)\end{array}$ & $\begin{array}{c}-0.095^{* * *} \\
(0.04)\end{array}$ \\
\hline Ideology & $\begin{array}{c}-0.132^{* * *} \\
(0.02)\end{array}$ & $\begin{array}{c}-0.117^{* * *} \\
(0.03)\end{array}$ & $\begin{array}{c}-0.033^{* * *} \\
(0.00)\end{array}$ & $\begin{array}{c}-0.035^{* * *} \\
(0.01)\end{array}$ \\
\hline Rents are problem & $\begin{array}{c}0.252^{* * *} \\
(0.02)\end{array}$ & $\begin{array}{c}0.237^{* * *} \\
(0.03)\end{array}$ & $\begin{array}{c}0.035^{* * *} \\
(0.00)\end{array}$ & $\begin{array}{c}0.041^{* * *} \\
(0.01)\end{array}$ \\
\hline Constant & $\begin{array}{c}1.146^{* * *} \\
(0.37)\end{array}$ & $\begin{array}{l}0.971^{*} \\
(0.51)\end{array}$ & $\begin{array}{c}0.382^{\text {*** }} \\
(0.07)\end{array}$ & $\begin{array}{c}0.315^{* * *} \\
(0.10)\end{array}$ \\
\hline $\begin{array}{l}\text { Trust only } \\
\text { Controls }\end{array}$ & $\begin{array}{l}\text { No } \\
\text { Yes }\end{array}$ & $\begin{array}{l}\text { Yes } \\
\text { Yes }\end{array}$ & $\begin{array}{l}\text { No } \\
\text { Yes }\end{array}$ & $\begin{array}{l}\text { Yes } \\
\text { Yes }\end{array}$ \\
\hline Observations & 3,030 & 1,767 & 3,030 & 1,767 \\
\hline$R^{2}$ & 0.536 & 0.582 & 0.268 & 0.307 \\
\hline
\end{tabular}

Table 2: OLS regression with support for rent control as dependent variable. Heteroscedasticityrobust standard errors in brackets below. *,**,*** indicate significance at the $10 \%, 5 \%$ and 1\% level, respectively. Quantity, Price and Expert are treatment indicators. Controls include nationality, gender, employment, income, education and a set of state-fixed effects. Controls are dummies indicating German nationality, gender, full time workers as well as income, education and state-fixed effects. High trust indicates self-reported high trust in the information treatments. 
a causal role in determining policy preferences. The effect size is thereby largest in the expert treatment, and roughly equal in the price and the quantity treatment. Again, the effects are larger for those individuals who report higher trust in the information provided to them, see columns (2) and (4). This finding highlights the key role that trust in expert knowledge plays in spreading knowledge 8

Other lessons from this empirical exercise are that (i) profit motives, (ii) fairness concerns and (iii) political ideology play an important role, independently of beliefs. That is, participants who expect to profit from rent control are more supportive of rent control (being a landlord likely captures a similar motive), people who believe that rent control is "fair" and people who lean more to the left are more supportive of rent control. Finally, participants who think the current level of rents in Germany is a problem are also more supportive of rent control.9

In order to better compare the relative predictive power of each regressor, we also conduct a (non-preregistered) dominance analysis (Azen and Budescu, 2003) 10 From the regression model in column (2) of Table 2 , we find that fairness contributes around $55 \%$ of the total predictive power of the empirical model, problem perception around $15 \%$ and profit around $13 \%$. The relative contribution of each treatment dummy, of political ideology and the landlord dummy lies below $10 \%$ in each case.

Finally, Tables 5 and 6 in the Appendix display regression results, in which other outcomes are used as right-hand variables. There, two results seem noteworthy. First, the expert treatment (but not the other two) significantly reduces support for price controls in general and reduces the perceived fairness of rent control (more so, among those who trust the information more). Second, all treatments reduce the perceived efficiency of rent control. Again, this effect is stronger for high-trusting individuals.

\footnotetext{
${ }^{8}$ Table 4 in the Appendix displays the results of a correlational exploration in which the prior beliefs, and not the treatment dummies, are included in the regressions. We find that priors correlate with preferences for rent control in the expected way, except that the price prior is not statistically significant in the "donation regression".

${ }^{9}$ Regarding the control variables, which are included in the regressions but not displayed in the table, we find that being male, holding a higher educational degree and earning a higher income are robustly associated with less support for rent control.

${ }^{10}$ This analysis uses the average difference in the $R^{2}$ between all subsets of models with and all subsets of models without $x_{i}$ to calculate the relative predictive power of $x_{i}$.
} 


\subsection{Heterogeneous Treatment Effects: Political Ideology and Education}

We put forward two different (pre-registered) additional hypotheses. The first hypothesis is that left-wingers hold less well-calibrated (too optimistic) beliefs about the effects of rent control and consequently update their priors more strongly than do right-wingers. The second hypothesis is that more educated participants hold better calibrated beliefs and update more strongly than do less educated participants. While the first hypothesis is supported by the data, the second is not 11

The top panels in Figure 3 show that left-wingers hold higher (less negative) quantitypriors, but also that they update more strongly (downwards). This asymmetric updating significantly closes the ideological gap in beliefs (left-hand panel). Regarding price beliefs, there is no such closing of the gap (right-hand panel). Instead, both right- and left-wingers engage in equally strong updating, which leads to parallel lines in the figure. As expected, both groups conduct virtually no updating in the control group. The main difference is that right-wingers start from a higher level of price beliefs, such that posteriors of rightwingers in the control group are virtually on the same level as posteriors of left-wingers in the treated group.

Interestingly, this asymmetric belief updating leads to a reduction in the left-right gap in support for rent control: while left-wingers reduce their support, the support of right-wingers is almost unaffected by the treatments (see Figure 5 in the Appendix). Consequently, the gap is reduced by about one-third relative to the control ${ }^{12}$

Regarding the second hypothesis, we find no evidence for differences in belief updating according to high or low education, see the two panels at the bottom of Figure 3 . As seen there, in each case the lines are parallel for treatment and control, respectively, indicating no differences in belief updating. These conclusions hold for both quantity and price beliefs.

\footnotetext{
${ }^{11}$ We define "high education" as having at least a high school diploma (at least a 4 on the 5 point education scale) and "right-wing" as indicating at least a 6 on the 1-11 ideology scale. Both definitions are basically median splits of the answers to the two underlying variables.

${ }^{12}$ The unconditional gap in support between left- and right-wingers is 1.4 in the control group. The same gap is 1.22 for quantity, 1.06 for price) and 1.03 for expert. Thus, the ideology gap is cut down by about $\frac{1.4-1.03}{1.03}=36 \%$ in the expert treatment. The same numbers are $15 \%$ (quantity) and $32 \%$ (price), respectively.
} 

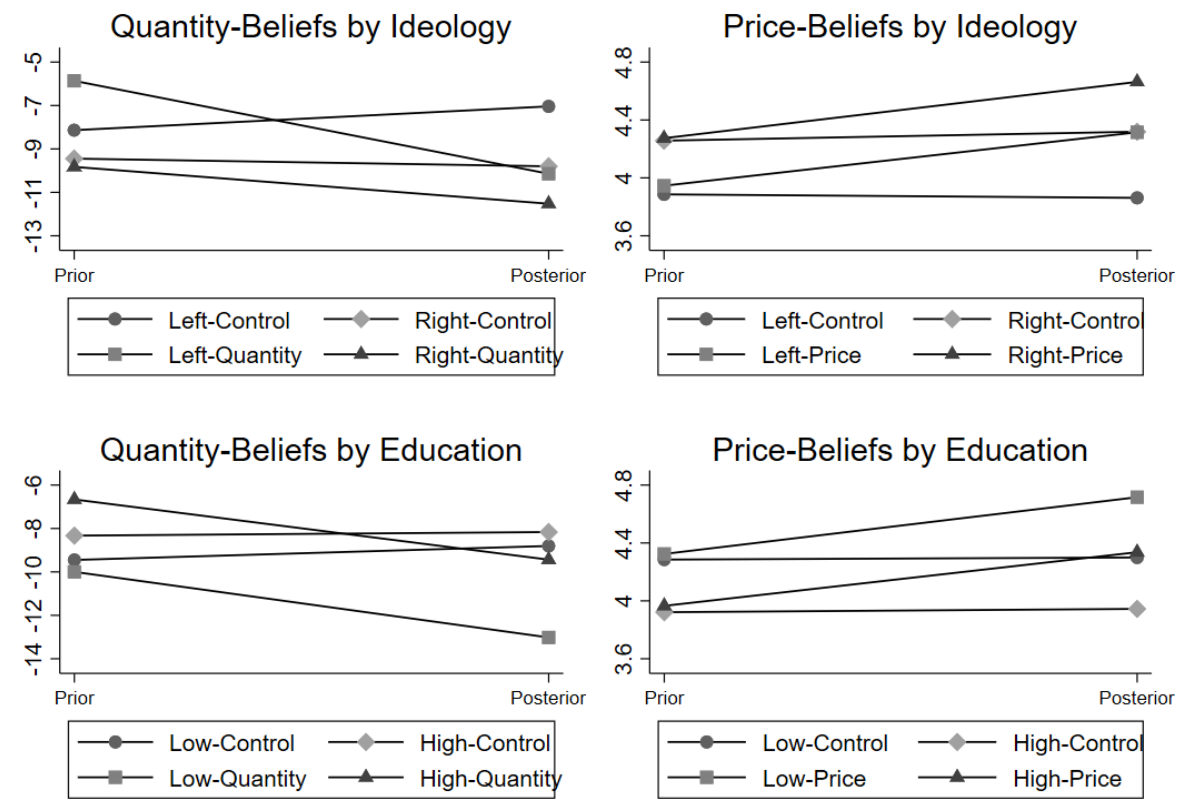

Figure 3: Belief updating by left- and right-wing political ideology (top panels) and by education (bottom panels). In the legend below the panels, left means left-winger, right means right-winger, low means low education and high means high education.

\section{Concluding Remarks}

Few endeavors seem more timely than understanding the disconnect between the opinions held by the general public and by experts. We aim to contribute to this question in the realm of economic policy. Indeed, the answer to this question is important to understand why people select policies that are overwhelmingly rejected by experts. The evidence presented in the current paper shows that there is a role for mis-calibrated beliefs. In particular, we find that people update their beliefs about the consequences of rent control in response to our treatments. However, it turns out that fairness considerations and selfish profit motives are more important than beliefs about the efficacy of the policy. Policy advice should thus not stop at providing information about scientific evidence and expert advice, but should also aim to understand more clearly people's notions of fairness and their expectations of profitability in the domain of economic policies. Moreover, our 
survey highlights the importance of trust in expert opinions since the treatment effects are consistently stronger for those who indicate trust in the information they were given. Our survey experiment thus suggests that it is important to understand what factors determine trust in expert advice and how to increase it.

An important question that the current paper cannot answer is why exactly people believe that rent control is fair (or not) - although we do find some evidence that they adjust their fairness evaluations in response to the treatments. Moreover, we cannot really answer the question whether such people hold well-calibrated beliefs with respect to the financial gains and losses they themselves experience from this policy. Again, the fact that participants do not adjust their profit expectations in response to the treatments suggests, on average, that they might misjudge the profitability of rent control and that correcting these beliefs could alter support for rent control.

\section{References}

Azen, R., And D. V. Budescu (2003): "The dominance analysis approach for comparing predictors in multiple regression," Psychological Methods, 8(2), 129-148.

Brandts, J., I. Busom, C. Lopez-Mayán, and J. Panadés (2019): "Dispelling Misconceived Beliefs about Rent Control: Insights from a Field and a Laboratory Experiment," Available at SSRN 3384538.

Caplan, B. (2002): "Systematically biased beliefs about economics: robust evidence of judgemental anomalies from the survey of Americans and economists on the economy," The Economic Journal, 112(479), 433-458.

Dal Bó, E., P. Dal Bó, and E. Eyster (2018): "The demand for bad policy when voters underappreciate equilibrium effects," The Review of Economic Studies, 85(2), 964-998.

Davis, L. W., And L. KILIAN (2011): "The allocative cost of price ceilings in the US residential market for natural gas," Journal of Political Economy, 119(2), 212-241.

Diamond, R., T. McQuade, And F. QIAn (2019): "The effects of rent control expan- 
sion on tenants, landlords, and inequality: Evidence from San Francisco," American Economic Review, 109(9), 3365-94.

Friedman, M., And G. J. Stigler (1946): Roofs or Ceilings?: The Current Housing Problem. Foundation for Economic Education.

Glaeser, E. L., and E. F. Luttmer (2003): "The misallocation of housing under rent control," American Economic Review, 93(4), 1027-1046.

HaAland, I., C. Roth, and J. Wohlfart (2021): "Designing information provision experiments," Journal of Economic Literature.

Haferkamp, A., D. Fetchenhauer, F. Belschak, and D. Enste (2009): "Efficiency versus fairness: The evaluation of labor market policies by economists and laypeople," Journal of Economic Psychology, 30(4), 527-539.

Jacob, R., F. Christandl, and D. Fetchenhauer (2011): "Economic experts or laypeople? How teachers and journalists judge trade and immigration policies," Journal of Economic Psychology, 32(5), 662-671.

Kallbekken, S., S. Kroll, and T. L. Cherry (2011): "Do you not like Pigou, or do you not understand him? Tax aversion and revenue recycling in the lab," Journal of Environmental Economics and Management, 62(1), 53-64.

Sapienza, P., And L. Zingales (2013): "Economic experts versus average Americans," American Economic Review: Papers and Proceedings, 103(3), 636-42.

Sausgruber, R., And J.-R. Tyran (2005): "Testing the Mill hypothesis of fiscal illusion," Public choice, 122(1-2), 39-68.

(2011): "Are we taxing ourselves?: How deliberation and experience shape voting on taxes," Journal of Public Economics, 95(1-2), 164-176.

Stantcheva, S. (2020): "Understanding tax policy: How do people reason?," NBER Working Paper. 


\section{Appendix}

\subsection{Additional Results}

\begin{tabular}{lccccc}
\hline \hline \multirow{2}{*}{ Confidence } & \multicolumn{2}{c}{ Posterior Quantity } & & \multicolumn{2}{c}{ Posterior Price } \\
\cline { 2 - 3 } \cline { 5 - 6 } & $(1)$ & $(2)$ & & $(3)$ & $(4)$ \\
\cline { 5 - 6 } Quantity & $0.244^{* * *}$ & $0.300^{* * *}$ & & 0.007 & 0.003 \\
& $(0.05)$ & $(0.06)$ & & $(0.05)$ & $(0.06)$ \\
Price & -0.059 & 0.011 & & -0.086 & -0.019 \\
& $(0.05)$ & $(0.07)$ & & $(0.05)$ & $(0.07)$ \\
Expert & -0.001 & 0.030 & & -0.056 & -0.092 \\
& $(0.05)$ & $(0.07)$ & & $(0.05)$ & $(0.07)$ \\
Constant & $2.652^{* * *}$ & $2.676^{* * *}$ & & $2.711^{* * *}$ & $2.860^{* * *}$ \\
& $(0.13)$ & $(0.18)$ & & $(0.13)$ & $(0.18)$ \\
\hline High trust only & No & Yes & No & Yes \\
Observations & 3,031 & 1,768 & 3,031 & 1,768 \\
$R^{2}$ & 0.081 & 0.091 & 0.047 & 0.046 \\
\hline \hline
\end{tabular}

Table 3: OLS regressions with heteroscedasticity-robust standard errors in brackets below. *, **, *** indicate significance at the $10 \%, 5 \%$ and $1 \%$ level, respectively. The dependent variable is the response to the question "How sure are you about your answer to the previous question?" following the posterior elicitation. Quantity, Price and Expert are treatment indicators. Columns (1) and (2) are quantity posteriors, columns (3) and (4) posteriors about the price reaction. Controls include nationality, gender, employment, income, education and a set of state-fixed effects. High trust indicates self-reported high trust in the information treatments. 

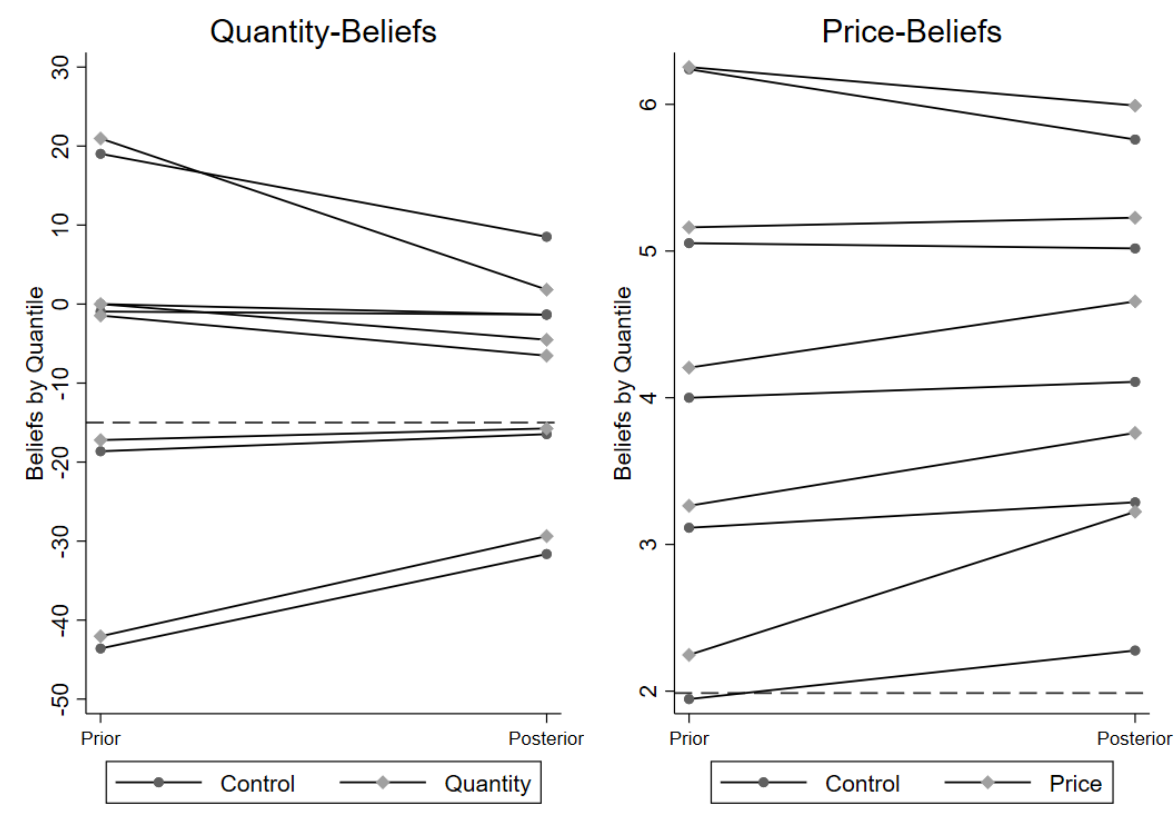

Figure 4: Belief updating: (i) supply reactions by (quantity) prior quantile separately for the quantity treatment and the control group (left-hand panel); (ii) about price reactions by (price) prior quantile separately for the price treatment and control group (right-hand panel). 


\begin{tabular}{|c|c|c|c|c|}
\hline & \multicolumn{2}{|c|}{ Support Rent Control } & \multicolumn{2}{|c|}{ Donation } \\
\hline & (1) & $(2)$ & $(3)$ & $(4)$ \\
\hline Prior Quantity & $\begin{array}{c}0.011^{* * *} \\
(0.00)\end{array}$ & $\begin{array}{c}0.013^{* * *} \\
(0.00)\end{array}$ & $\begin{array}{c}0.001^{* * *} \\
(0.00)\end{array}$ & $\begin{array}{c}0.002^{* * *} \\
(0.00)\end{array}$ \\
\hline Prior Price & $\begin{array}{c}-0.080^{* * *} \\
(0.02)\end{array}$ & $\begin{array}{c}-0.062^{* *} \\
(0.03)\end{array}$ & $\begin{array}{c}-0.003 \\
(0.00)\end{array}$ & $\begin{array}{l}0.003 \\
(0.01)\end{array}$ \\
\hline Fairness & $\begin{array}{c}1.222^{* * *} \\
(0.05)\end{array}$ & $\begin{array}{c}1.324^{* * *} \\
(0.07)\end{array}$ & $\begin{array}{c}0.126^{* * *} \\
(0.01)\end{array}$ & $\begin{array}{c}0.135^{* * *} \\
(0.01)\end{array}$ \\
\hline Profit & $\begin{array}{c}0.210^{* * *} \\
(0.02)\end{array}$ & $\begin{array}{c}0.206^{* * *} \\
(0.03)\end{array}$ & $\begin{array}{c}0.011^{* *} \\
(0.00)\end{array}$ & $\begin{array}{c}0.012^{* *} \\
(0.01)\end{array}$ \\
\hline Landlord & $\begin{array}{c}-0.649^{* * *} \\
(0.12)\end{array}$ & $\begin{array}{c}-0.562^{* * *} \\
(0.14)\end{array}$ & $\begin{array}{c}-0.095^{* * *} \\
(0.03)\end{array}$ & $\begin{array}{c}-0.089^{* *} \\
(0.04)\end{array}$ \\
\hline Ideology & $\begin{array}{c}-0.118^{* * *} \\
(0.02)\end{array}$ & $\begin{array}{c}-0.115^{* * *} \\
(0.03)\end{array}$ & $\begin{array}{c}-0.032^{* * *} \\
(0.00)\end{array}$ & $\begin{array}{c}-0.035^{* * *} \\
(0.01)\end{array}$ \\
\hline Rents are problem & $\begin{array}{c}0.266^{* * *} \\
(0.02)\end{array}$ & $\begin{array}{c}0.251^{* * *} \\
(0.03)\end{array}$ & $\begin{array}{c}0.036^{* * *} \\
(0.00)\end{array}$ & $\begin{array}{c}0.042^{* * *} \\
(0.01)\end{array}$ \\
\hline Constant & $\begin{array}{c}1.481^{* * *} \\
(0.39)\end{array}$ & $\begin{array}{c}1.062^{* *} \\
(0.53)\end{array}$ & $\begin{array}{c}0.407^{* * *} \\
(0.08)\end{array}$ & $\begin{array}{c}0.341^{* * *} \\
(0.10)\end{array}$ \\
\hline Trust only & No & Yes & No & Yes \\
\hline Controls & Yes & Yes & Yes & Yes \\
\hline Observations & 3,030 & 1,767 & 3,030 & 1,767 \\
\hline$R^{2}$ & 0.541 & 0.582 & 0.272 & 0.309 \\
\hline
\end{tabular}

Table 4: OLS regression with support for rent control on a 1-10 scale, where 10 means "full support" as dependent variable. Heteroscedasticity-robust standard errors in brackets below. *, **, ${ }^{* * *}$ indicate significance at the $10 \%, 5 \%$ and $1 \%$ level, respectively. Quantity, Price and Expert are treatment indicators. Includes only participants that passed the attention checks. Controls include nationality, gender, employment, income, education and a set of state-fixed effects. High trust indicates self-reported high trust in the information treatments. 


\begin{tabular}{|c|c|c|c|c|c|c|}
\hline & \multicolumn{2}{|c|}{ Support price controls } & \multicolumn{2}{|c|}{ Ideology } & \multicolumn{2}{|c|}{ Support free markets } \\
\hline & $(1)$ & $(2)$ & $(3)$ & $(4)$ & $(5)$ & (6) \\
\hline \multirow[t]{2}{*}{ Quantity } & -0.033 & -0.240 & 0.148 & $0.243^{* *}$ & -0.010 & 0.119 \\
\hline & $(0.13)$ & $(0.17)$ & $(0.10)$ & $(0.12)$ & $(0.10)$ & $(0.13)$ \\
\hline \multirow[t]{2}{*}{ Price } & 0.049 & -0.077 & 0.073 & 0.134 & -0.127 & -0.041 \\
\hline & $(0.13)$ & $(0.18)$ & $(0.10)$ & $(0.13)$ & $(0.10)$ & $(0.13)$ \\
\hline \multirow[t]{2}{*}{ Expert } & $-0.324^{* *}$ & $-0.529^{* * *}$ & 0.016 & 0.150 & -0.008 & 0.183 \\
\hline & $(0.13)$ & $(0.17)$ & $(0.09)$ & $(0.13)$ & $(0.10)$ & $(0.13)$ \\
\hline \multirow[t]{2}{*}{ Constant } & $7.657^{* * *}$ & $8.577^{* * *}$ & $5.573^{* * *}$ & $5.082^{* * *}$ & $5.315^{* * *}$ & $5.282^{* * *}$ \\
\hline & $(0.35)$ & $(0.46)$ & $(0.24)$ & $(0.33)$ & $(0.27)$ & $(0.34)$ \\
\hline Trust only & No & Yes & No & No & No & Yes \\
\hline Controls & Yes & Yes & Yes & Yes & Yes & Yes \\
\hline Observations & 3,031 & 1,768 & 3,031 & 1,768 & 3,030 & 1,767 \\
\hline$R^{2}$ & 0.068 & 0.096 & 0.070 & 0.079 & 0.054 & 0.063 \\
\hline
\end{tabular}

Table 5: OLS regression with different outcome variables as dependent variable. Heteroscedasticityrobust standard errors in brackets below. *, **, *** indicate significance at the $10 \%, 5 \%$ and $1 \%$ level, respectively. Quantity, Price and Expert are treatment indicators. Includes only participants that passed the attention checks. Controls include nationality, gender, employment, income, education and a set of state-fixed effects. High trust indicates self-reported high trust in the information treatments. 


\begin{tabular}{|c|c|c|c|c|c|c|c|c|}
\hline & \multicolumn{4}{|c|}{ Mechanisms } & \multicolumn{4}{|c|}{ Consequences } \\
\hline & \multicolumn{2}{|c|}{ Fairness } & \multicolumn{2}{|c|}{ Profit } & \multicolumn{2}{|c|}{ Rent longer } & \multicolumn{2}{|c|}{ Efficiency } \\
\hline & (1) & $(2)$ & $(3)$ & (4) & $(5)$ & (6) & $(7)$ & $(8)$ \\
\hline \multirow[t]{2}{*}{ Quantity } & $-0.090^{*}$ & -0.099 & 0.021 & 0.000 & -0.041 & 0.051 & $-0.099^{* *}$ & $-0.172^{* * *}$ \\
\hline & $(0.05)$ & $(0.06)$ & $(0.08)$ & $(0.11)$ & $(0.05)$ & $(0.06)$ & $(0.05)$ & $(0.06)$ \\
\hline \multirow[t]{2}{*}{ Price } & -0.056 & $-0.114^{*}$ & 0.029 & -0.025 & -0.074 & -0.034 & -0.058 & $-0.211^{* * *}$ \\
\hline & $(0.05)$ & $(0.07)$ & $(0.08)$ & $(0.11)$ & $(0.05)$ & $(0.07)$ & $(0.05)$ & $(0.07)$ \\
\hline \multirow[t]{2}{*}{ Expert } & $-0.094^{* *}$ & $-0.219^{* * *}$ & -0.026 & -0.159 & -0.073 & -0.042 & $-0.094^{*}$ & $-0.246^{* * *}$ \\
\hline & $(0.05)$ & $(0.06)$ & $(0.08)$ & $(0.10)$ & $(0.05)$ & $(0.06)$ & $(0.05)$ & $(0.07)$ \\
\hline \multirow[t]{2}{*}{ Constant } & $3.650^{* * *}$ & $4.000^{* * *}$ & $5.715^{* * *}$ & $5.878^{* * *}$ & $3.738^{* * *}$ & $3.862^{* * *}$ & $2.233^{* * *}$ & $2.279^{* * *}$ \\
\hline & $(0.13)$ & $(0.18)$ & $(0.21)$ & $(0.29)$ & $(0.12)$ & $(0.17)$ & $(0.13)$ & $(0.17)$ \\
\hline Trust only & No & Yes & No & No & No & Yes & No & Yes \\
\hline Controls & Yes & Yes & Yes & Yes & Yes & Yes & Yes & Yes \\
\hline Observations & 3,030 & 1,767 & 3,030 & 1,767 & 3,031 & 1,768 & 3,031 & 1,768 \\
\hline$R^{2}$ & 0.040 & 0.060 & 0.032 & 0.031 & 0.009 & 0.017 & 0.022 & 0.026 \\
\hline
\end{tabular}

Table 6: OLS regression with different outcome variables as dependent variable. Heteroscedasticityrobust standard errors in brackets below. *, **, *** indicate significance at the $10 \%, 5 \%$ and $1 \%$ level, respectively. Quantity, Price and Expert are treatment indicators. Includes only participants that passed the attention checks. Controls include nationality, gender, employment, income, education and a set of state-fixed effects. High trust indicates self-reported high trust in the information treatments. 


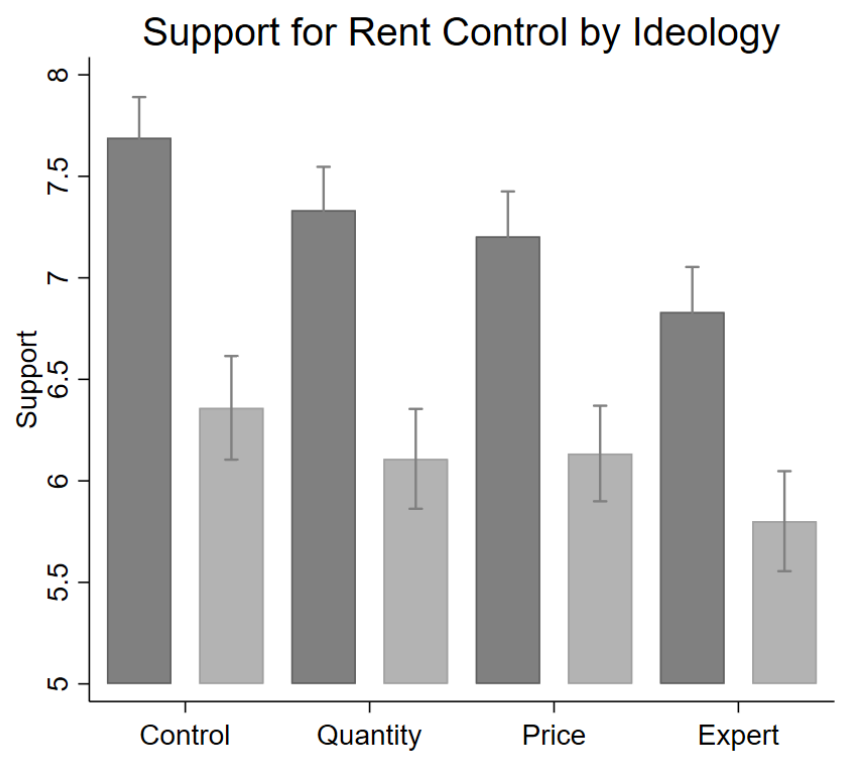

Figure 5: Support for rent control by left- and right-wing political ideology, separately for each treatment. Darker color indicates left-wingers, brighter color right-wingers. Whiskers indicate $95 \%$ confidence intervals. 


\subsection{Follow-up Survey}

We also conducted an obfuscated (and not pre-registered) follow-up survey, in which we recontacted $50 \%$ of the participants who passed the attention checks in the main survey. We used the follow-up survey to measure the persistence of the information treatment effects over time. Hence, we again elicit participants' beliefs about the effects of rent control policies on housing supply and rent prices and we also elicit participants' support for rent control. Specifically, the follow-up was presented as unrelated to the main study and also contained a range of independent questions about different economic policies such as tax policy preferences and preferences for redistribution 13 To further veil the connection to the main survey, we also changed the survey layout and length.

Regarding the persistence of the effect of the quantity treatment, the left panel in Figure 6 shows the evolution of beliefs by treatment. The panel shows that while beliefs of subjects in the quantity treatment are still below those of the other treatments in the follow-up survey, they are up from $-11 \%$ (posteriors in the main survey) to $-8 \%$. Column (1) in Table 7 shows that the difference is not significant, on average. Column (2), on the other hand, displays a quantitatively large, negative coefficient of around $-4 \%$ on the quantity dummy for those who trusted the information provided to them. The coefficient is, however, significant only at the $10 \%$ level, suggesting that the follow-up might suffer from low statistical power 14

The right-hand panel in Figure 6 displays the evolution of price beliefs and shows signs of full reversal of the effect of the price treatment in the follow-up. Consistent with the conclusion stated one paragraph above, columns (3) and (4) in Table 7 deliver weak evidence for the persistence of the effect among those in the price treatment who trusted the study. Moreover, the coefficient on the expert dummy is statistically significant, highlighting again the greater efficiency of this treatment.

Regarding (stated) support for rent control, the difference in support between the quantity treatment and the control is virtually nullified in the follow-up survey (down from $\frac{7-6.7}{6.7}=4.8 \%$ in the main survey). The effects of the other two treatments are roughly

\footnotetext{
${ }^{13}$ The translated follow-up survey can be found in the Supplementary File.

${ }^{14}$ Another sign for not enough statistical power is the fact that the standard errors are roughly twice as large as the standard errors in the comparable regressions in the main text. Thus, all these results regarding the follow-up should accordingly be interpreted with caution.
} 
bisected: the difference between the price treatment and the control is reduced to $3.0 \%$, down from $4.9 \%$. In the expert treatment, the difference is $4.3 \%$, down from $10.1 \%$. Figure 7 displays the average support by treatment in the main and the follow-up surveys.
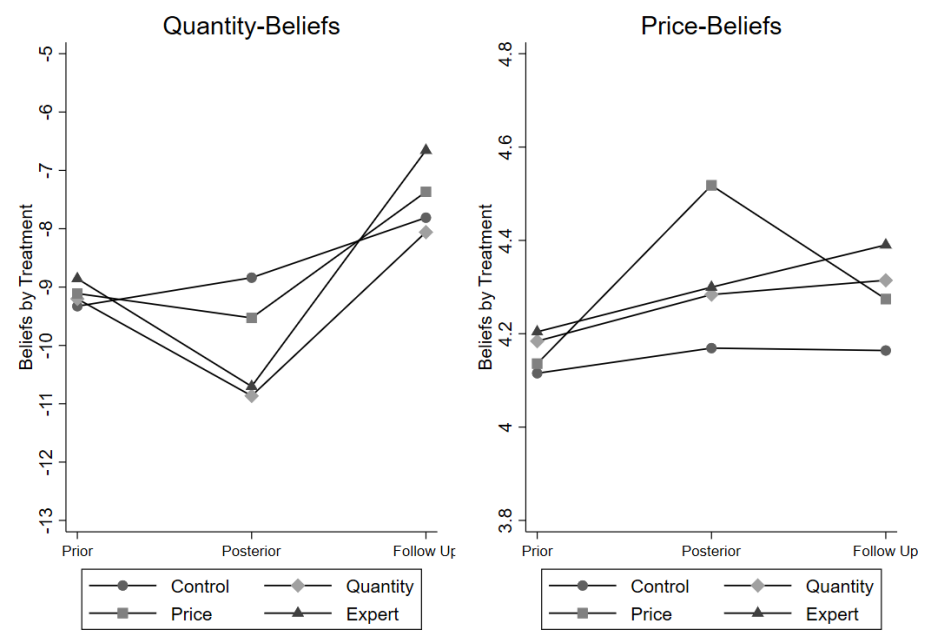

Figure 6: Belief updating from main- to follow-up survey.

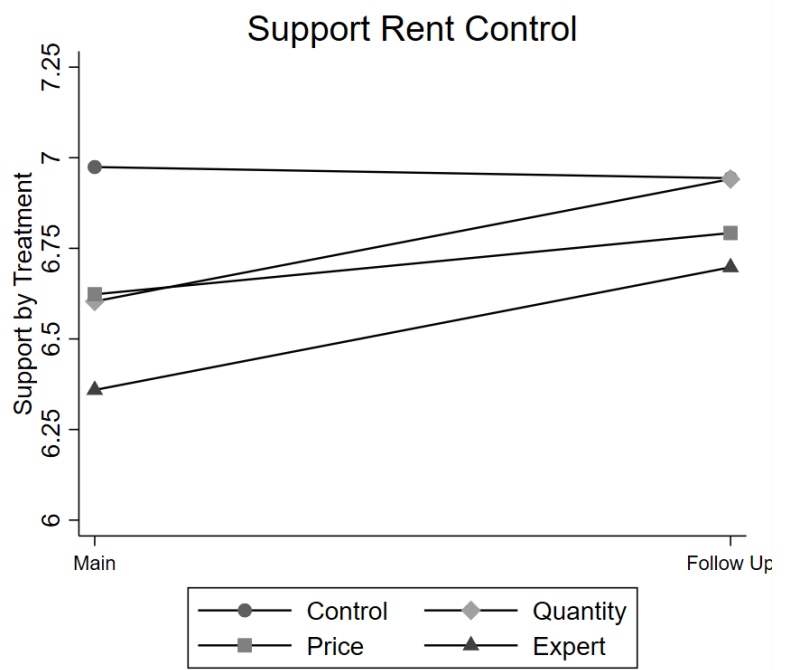

Figure 7: Development of support for rent control from main to follow-up survey. 


\begin{tabular}{lccccc}
\hline \hline & \multirow{2}{*}{ Quantity Beliefs } & & \multicolumn{2}{c}{ Price Beliefs } \\
\cline { 5 - 6 } & $(1)$ & $(2)$ & & $(3)$ & $(4)$ \\
\hline Quantity & 0.416 & $-4.019^{*}$ & & 0.139 & 0.133 \\
& $(1.75)$ & $(2.14)$ & & $(0.11)$ & $(0.14)$ \\
Price & 0.670 & -0.484 & 0.135 & $0.255^{*}$ \\
& $(1.80)$ & $(2.38)$ & & $(0.11)$ & $(0.14)$ \\
Expert & 1.539 & -2.770 & $0.235^{* *}$ & $0.297^{* *}$ \\
& $(1.78)$ & $(2.29)$ & & $(0.11)$ & $(0.14)$ \\
Constant & -7.637 & -6.474 & $4.511^{* * *}$ & $4.772^{* * *}$ \\
& $(4.65)$ & $(6.05)$ & $(0.29)$ & $(0.40)$ \\
\hline Trust only & No & Yes & No & Yes \\
Controls & Yes & Yes & Yes & Yes \\
\hline Observations & 1,454 & 870 & 1,454 & 870 \\
$R^{2}$ & 0.008 & 0.013 & 0.026 & 0.030 \\
\hline \hline
\end{tabular}

Table 7: Follow-up survey. OLS regression with quantity and price beliefs as dependent variable. Heteroscedasticity-robust standard errors in brackets below. ${ }^{*}, * *, * * *$ indicate significance at the 10\%, 5\% and 1\% level, respectively. Quantity, Price and Expert are treatment indicators. Includes only participants that passed the attention checks. Controls include nationality, gender, employment, income, education and a set of state-fixed effects. High trust indicates self-reported high trust in the information treatments.

\subsection{Survey Design}


Enter the survey experiment

$\downarrow$

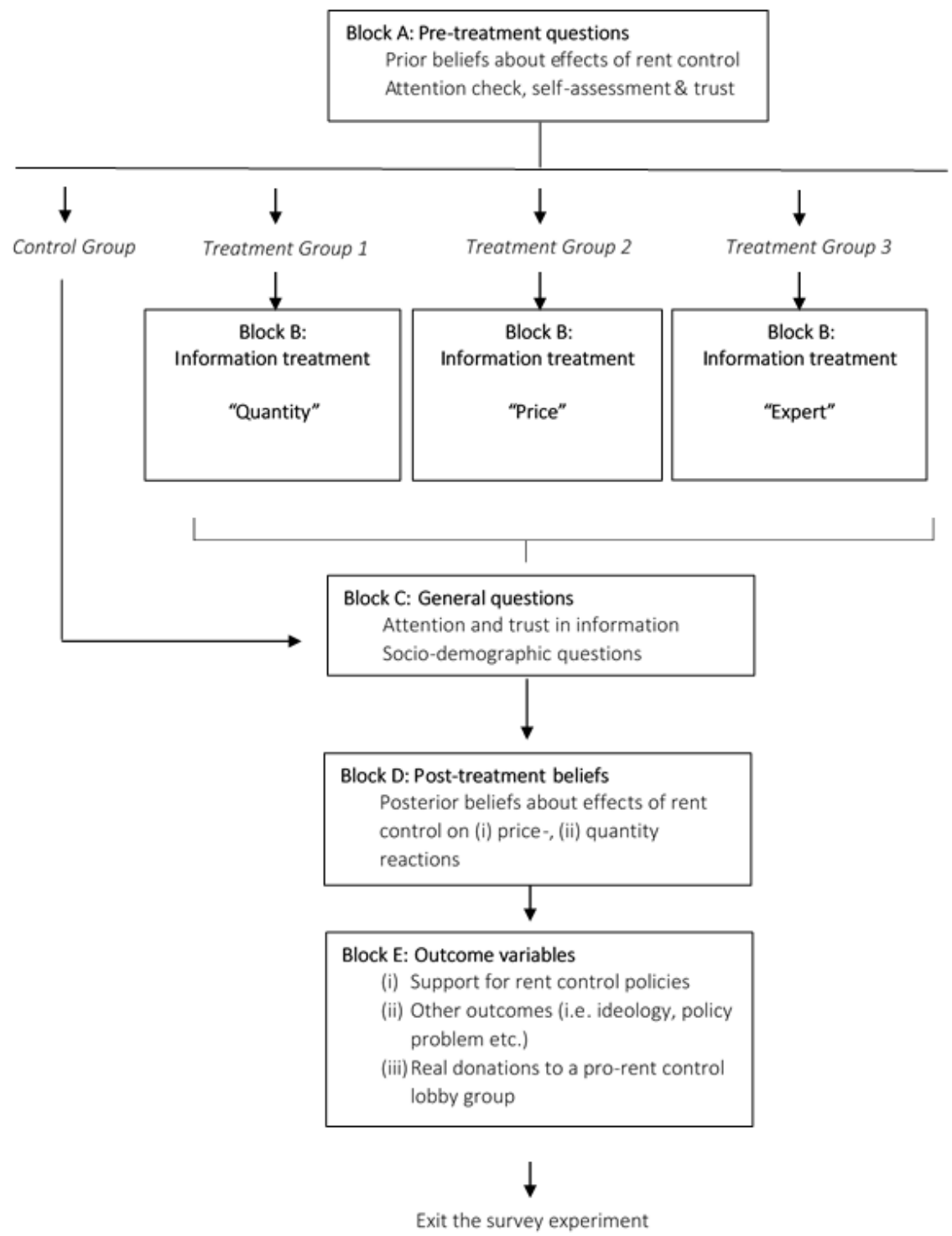

Figure 8: Overview of the main survey. 


\begin{tabular}{|c|c|c|}
\hline Main Variables & Question No. & Coding \\
\hline \multicolumn{3}{|l|}{ Beliefs } \\
\hline Belief supply & 1 & slider: $0 \%-100 \%$ \\
\hline Belief price & 3 & 1 (much lower) - 7 (much higher) \\
\hline \multicolumn{3}{|l|}{ Support rent control } \\
\hline Stated support & 29 & 1 (strongly oppose) - 10 (strongly support) \\
\hline Donation & 41 & $1=$ pro-rent control; $0=$ otherwise \\
\hline \multicolumn{3}{|l|}{ Trust in Information } \\
\hline Trust Study & 10 & $\begin{array}{l}1 \text { (low trust) }-5 \text { (high trust), } \\
\text { high trust }=1 \text { if trust }>3,0=\text { otherwise }\end{array}$ \\
\hline \multicolumn{3}{|l|}{ Additional Variables } \\
\hline Support price control & 30 & 1 (strongly oppose) - 10 (strongly support) \\
\hline Ideology & 31 & 1 (far left) - 11 (far right) \\
\hline Fairness rent control & 32 & 1 (unfair) - 5 (fair) \\
\hline Support free markets & 38 & 1 (strongly disagree) - 10 (strongly agree) \\
\hline Profit & 34 & 1 (hurt very much) - 10 (benefit very much) \\
\hline Rent longer & 27 & 1 (no effect) - 10 (very strong effect) \\
\hline Problem efficiency & 28 & 1 (no problem) - 5 (very severe) \\
\hline Rents are problem & 32 & 1 (no problem) - 10 (very severe) \\
\hline \multicolumn{3}{|l|}{ Socio-Demographics } \\
\hline German nationality & 11 & $1=$ yes, $0=$ otherwise \\
\hline Gender & 12 & $1=$ male, $0=$ otherwise \\
\hline Age & 13 & in years \\
\hline Education & 15 & 1 (no formal education) - 5 (university degree) \\
\hline Income & 14 & 12 income brackets for net income, variable divided by 1000 \\
\hline Employment & 18 & $1=$ full time, $0=$ otherwise \\
\hline Renting status & 20 & $1=$ renting, $0=$ otherwise \\
\hline Landlord & 22 & $1=$ landlord, $0=$ otherwise \\
\hline
\end{tabular}




\section{Supplementary File}

\section{Experimental Instructions}

\subsection{Main survey}

\section{Welcome and Consent}

Welcome to our survey on economic policy and real estate markets. This survey is conducted by the Ludwig-Maximilian-University of Munich and the University of Innsbruck. Please note that it is very important for the validity of our survey that you read the questions very carefully before answering. If at any time you do not know an answer, please provide your best guess without consulting outside sources. However, please make sure that you take enough time to read and understand the questions. It is also very important to the success of our research project that you complete the entire survey once you have started. Completing this survey should take (on average) about 10 minutes. Your participation in this study is completely voluntary and anonymous. Your name will not be stored at any time. Your answers will be used in a scientific study and will be processed in aggregated form. No one can draw conclusions about your identity from your answers.

O Yes, I would like to participate in this study and confirm that I live in Germany and am at least 18 years old.

O No, I do not wish to participate

\section{Device}

On which end device are you completing this survey? [PC/desktop; tablet; mobile device (cell phone, smartphone)] 


\section{Pre-treatment beliefs}

We would now like to ask you about your assessments of the housing market. As you may have heard, the "Mietpreisbremse" [rent control policy], which is also known as "Mietpreisbindung", "Mietenstopp" or "Mietendeckel", is a legal measure to curb the rise in rents and to continue to enable affordable housing. Where the rent cap applies, a cap is placed on the amount of rent or a restriction applies to rent increases.

Next, we will ask you to provide your assessment of the impact of the "Mietpreisbremse" on the supply of housing and on the level of rent prices.

1. What do you think is the medium-term effect, i.e., the effect after about 5-10 years, of rent control on the supply of rental housing? Will rent control increase, keep the same or decrease the number of apartments in the housing market?

o With rent control, more apartments will be offered than without rent control.

o With rent control, approximately the same number of apartments will be offered as without rent control.

o With rent control, fewer apartments are offered than without rent control.

If: more or fewer

By what percentage will the supply of rental housing increase/decrease as a result of the rent control? You can indicate your answer on a scale from $0 \%$ to $100 \%$.

If: same [Skip to next question]

2. How sure are you about your answer to the previous question? [1-5; Very unsure, Very sure]

3. What do you think is the medium-term effect, i.e., the effect after about 5-10 years, of rent control on the level of rents? Will rent control cause rents to increase, decrease, or remain unchanged? 
o With rent control, rents will be much lower than without rent control.

o With rent control, rents will be lower than without rent control.

o With rent control, rents will be slightly lower than without rent control.

o With rent control, rents will remain roughly the same as without rent control.

o With rent control, rents will be slightly higher than without rent control.

o With rent control, rents will be higher than without rent control.

o With rent control, rents will be much higher than without rent control.

4. How sure are you about your answer to the previous question? [1-5; Very unsure, Very sure]

5. Do you think rent control will increase the likelihood that existing tenants will stay in your apartment longer than planned? [1-5; No, Not at all, Yes, Very much]

\section{Attention Check}

The next question relates to the following problem. In questionnaires like ours, there are sometimes participants who do not read the questions carefully and just click through the survey quickly. This means that there are a lot of random answers that affect the results of research studies. To show that you read through our questions carefully, please enter "brown" as the answer to the next question.

6. What is your favorite color? [Open text]

\section{Self-Assessment and Trust in Economists}

7. How competent would you consider yourself in the area of economic policy, e.g. tax policy, labor markets, or competition policy? [1-7; not at all competent, very competent]

8. Economists deal with the analysis of economic relationships, e.g. macroeconomic aspects such as taxes and unemployment. From their studies, they derive forecasts and recommendations for economic policy action. How much do you trust economists and their expertise 
in economic policy issues? [1-5, trust completely, somewhat, neutral, rather not, not at all]

\section{Treatment Price}

Next, we would like to provide you with information on the topic of rent control. A study by economists, which appeared in a respected academic journal, looks at how a rent control in the city of San Francisco in the United States has affected the real estate market there. The authors conclude that the rent control policy likely drove up market rents in the long run, ultimately undermining the policy's goals.

\section{Treatment Quantity}

Next, we would like to provide you with information on the topic of rent control policy. A study by economists, which appeared in a respected academic journal, looks at how a rent control in the city of San Francisco in the United States has affected the real estate market there. This study finds that after the introduction of the rent control, the supply of rental housing decreased by 15 percent 5-10 years later, meaning that the number of rental homes decreased. The reason for this is, among other things, that landlords are selling their own apartments or no longer renting them out and instead using them for themselves.

\section{Treatment Expert}

Next, we would like to provide information on the topic of rent control policy. Most economists and economic experts oppose a rent control law. According to a survey* of renowned economics professors from top universities, more than $80 \%$ of participating economists oppose rent control due to predominantly negative effects on the housing market, which harms tenants and landlords in the long run. ${ }^{1}$

\section{Control Group}

Next, we would like to provide you with information on the topic of Brexit, i.e. the United Kingdom's exit from the European Union. According to a 2020 study by the German Federal Statistical Office, Brexit will also have consequences for trade between Germany and the United Kingdom. For example, the amount of German exports to the United Kingdom

\footnotetext{
${ }^{1}$ Source: IGM Economic Experts Survey Panel ('IGM Economic Experts Panel'): www.igmchicago.org.
} 
has decreased compared to the previous year (2019).

\section{Attention and Trust in Information}

9. To ensure that you have also read the results of the previous study, we would like you to answer the following question: What set of issues was being examined in the indicated study? [Brexit; Corona; Housing market; Labor market]

10. How credible did you find the information provided by the study? [1-5; low trust, high trust]

\section{Socio-Demographic Questions}

11. Were you born in Germany [Yes, No]

12. Please state your gender. Are you... [male, female, diverse]?

13. Please state your age: [Open numeric]

14. What is your personal net monthly income? [below 500, 501-1000, 1001-1500, 15012000, 2001-2500; 2501-3000, 3001-3500; 3501-4000, 4001-5000,5001-6000, 6001-7000, above $7000]$

15. What is your highest level of education? [(still) no degree, secondary school diploma, secondary school diploma (secondary school, technical secondary school, or similar), high school diploma (general university entrance qualification, subject-specific university entrance qualification or university of applied sciences entrance qualification), university degree (bachelor's degree, master's degree, diploma, state examination, doctorate]

16. How many people live permanently in your household, including yourself? $[1,2,3,4$, 5 , more than 5]

17. What are the first two digits of the postal code of your place of residence? [Open 
numeric]

18. Are you currently ... [employed full time, employed part time, trainee, vocational training, self-employed, unemployed, retired, housewife/ husband]

19. How big is your apartment (in m2)? If you are not sure, please give an estimate. [Open numeric]

20. Is it a rented apartment or do you own the apartment? [rented apartment, owned apartment]

21. Is it difficult to find affordable rental housing where you live? [1-5; very difficult, very easy]

22. Do you currently rent out an apartment you own? [Yes, No]

\section{Post-Treatment Beliefs}

Rent control policies have also been introduced in some German cities. Next, we ask you to give your assessment of the impact of the "Mietpreisbremse" on the supply of apartments and on rent prices in German cities.

23. What do you think is the medium-term effect, i.e., the effect after about 5-10 years, of rent control on the supply of rental housing? Will rent control increase, keep the same or decrease the number of apartments in the housing market?

o With rent control, more apartments will be offered than without rent control.

o With rent control, approximately the same number of apartments will be offered as without rent control.

o With rent control, fewer apartments are offered than without rent control.

If: more or fewer 
By what percentage will the supply of rental housing increase/decrease as a result of the rent control? You can indicate your answer on a scale from $0 \%$ to $100 \%$.

If: same [Skip to next question]

24. How sure are you about your answer to the previous question? [1-5; very unsure, very sure]

25. What do you think is the medium-term effect, i.e., the effect after about 5-10 years, of rent control on the level of rents? Will rent control cause rents to increase, decrease, or remain unchanged?

o With rent control, rents will be much lower than without rent control.

o With rent control, rents will be lower than without rent control.

o With rent control, rents will be slightly lower than without rent control.

o With rent control, rents will remain roughly the same as without rent control.

o With rent control, rents will be slightly higher than without rent control.

o With rent control, rents will be higher than without rent control.

o With rent control, rents will be much higher than without rent control.

26. How sure are you about your answer to the previous question? [1-5; very unsure, very sure]

27. What do you think is the effect of rent control on the likelihood of existing tenants staying longer in their home, i.e., protecting tenants from being forced to move because of rising rents? [1-10; no effect, very strong effect]

28. If rent control applies, then it could be that the person who values the apartment most does not always get it. How severe do you think this problem is? [1-5, no problem, very severe] 


\section{Stated Support Rent Control}

29. How much do you support or oppose rent control policy, i.e. the introduction of a price cap on rents? [1-10; very strongly oppose, very strongly support]

\section{Additional Attitudes}

30. Do you generally support government interventions such as statutory price ceilings or floors? Note: Price floors are minimum prices set by law, such as minimum prices for agricultural products, rent control or the minimum wage. Price ceilings are maximum prices set by law, such as rent limits. [1-10; very strongly opposed, very strongly support]

31. Politically more right-wing parties traditionally tend to favor a policy of free markets and are thus opposed government intervention such as price controls. Parties on the left, on the other hand, often advocate state intervention in price formation. Thinking of your own economic policy views, where would you rank these views? [1-11; far left, far right]

32. Do you think the average level of rent prices in Germany is a problem? [1-10; no problem, very severe]

33. Do you agree with the following statement: [1-10; strongly disagree, strongly agree] I am afraid that I will not be able to afford my current apartment in the foreseeable future because of rising rents

34. Do you think you would benefit financially from the introduction of a rent control policy? [1-10; 1 - hurt very much ; 5 - no change, 10 - benefit very much]

35. Do you think rent control in Germany is a fair policy? [1-5; unfair, fair]

36. How do you think rent prices in Germany will develop in the medium term? [increase strongly, increase, stay the same, decrease, decrease strongly]

37. How do you think the supply of housing in Germany will develop in the medium term? 
(rise sharply, rise, stay the same, fall, fall sharply)

38. Do you agree with the following statement: [1-10; strongly disagree, strongly agree] The market economy and the free market are a good thing

39. Have you heard about the April 2021 Constitutional Court ruling that addressed the rent cap policy in Berlin? [Yes, No]

40. The Federal Constitutional Court has declared the Berlin rent cap unconstitutional. Would you agree to a constitutionally correct reintroduction of the rent cap in Berlin? [1-10; No, absolutely against, Yes, absolutely in favor]

\section{Revealed Support for Rent Control}

In Germany, there are various initiatives that represent different points of view on rent control policy. We have selected two initiatives and you can decide which of them you would like to support with an amount of 100 Euros. The two selected initiatives are the "Alternative Tenant and Consumer Protection Association", which advocates a tightening of rent control policy, and "ECONWATCH - Society for Policy Analysis", which condemns rent control policies. Your task now is to allocate the amount of 100 euros to one of the two organizations. At the end of the survey we will randomly select one participant and we will donate the amount of 100 Euros according to the decision made by the selected participant. Since each participant has an equal chance of being selected, it is important to make your decision as if you were donating your own money. Your allocation can determine which organization receives a donation that helps support their cause.

o I would like to donate 100 Euro to "Alternative Tenant and Consumer Protection Association"

o I would like to donate 100 Euro to "ECONWATCH - Society for Policy Analysis" 


\subsection{Screenshots Main Survey}

Was glauben Sie ist der mittelfristige Effekt, d.h. der Effekt nach ca. 5-10 Jahren, der Mietpreisbremse auf das Angebot von Mietwohnungen? Wird die Mietpreisbremse die Anzahl der Wohnungen am Wohnungsmarkt erhöhen, gleichbleiben lassen oder senken?

Mit Mietpreisbremse werden mehr Wohnungen als ohne Mietpreisbremse angeboten. Mit Mietpreisbremse werden ungefähr gleich viele Wohnungen wie ohne Mietpreisbremse angeboten.

Mit Mietpreisbremse werden weniger Wohnungen als ohne Mietpreisbremse angeboten.

Um wie viel Prozent steigt das Angebot an Mietwohnungen durch die Mietpreisbremse?

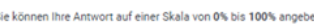

Änderung Angebot in \%

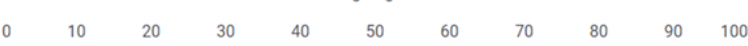

Figure 1: Prior quantity.

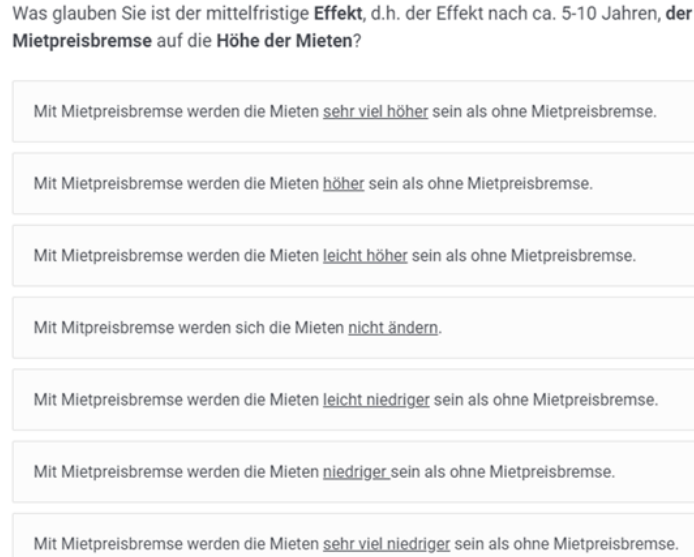

Figure 2: Prior price. 


\subsection{Follow-up survey}

\section{Welcome and Consent}

Welcome! This survey is being conducted to gain insight into your views on taxes and other policy instruments. The survey should take no longer than 5 minutes to complete. Any answers you give will be kept completely confidential and we will not be able to infer your identity from your answers. If you are at least 18 years old and would like to take part in this survey, please click Next to start the survey.

\section{Socio-Demographic Questions}

1. Your gender? [male/female]

2. How old are you? [18-24, 25-34, 35-44, 45-54, 55-64, ¿65]

3. What is your highest level of education? [(still) no qualification, secondary school leaving certificate, secondary school leaving certificate (secondary school, technical secondary school, or similar), high school leaving certificate (general university entrance qualification, subject-specific university entrance qualification or entrance qualification for a university of applied sciences), (technical) university degree (bachelor's, master's, diploma, state examination, doctorate]

\section{Attention Check}

4. This question is about the following problem. In questionnaires like ours, there are sometimes participants who don't read the questions carefully and just click through the survey quickly. This means that there are a lot of random answers that affect the results of research studies. To show that you have read our questions carefully, please select "I don't want to answer that" as your answer for the next question.

How interested are you in the European Football Championship?

o Very interested.

o Interested.

o A bit interested. 
o Not interested.

o Not at all interested.

o I don't want to answer that.

\section{Filler Question}

5. In the following we would like you to rate different fiscal and political measures that are often discussed in the media. Please use a scale of 1-10 to indicate whether you are in favor or against a measure. [1-10; Very strongly against - very strongly in favor]

o Income tax should be lowered.

o The minimum wage should be increased.

o Value added tax should be lowered.

o An unconditional basic income should be introduced.

\section{Beliefs}

Rent control policies have also been introduced in some German cities. Next, we ask you to give your assessment of the impact of the "Mietpreisbremse" on the supply of apartments and on rent prices in German cities.

6. What do you think is the medium-term effect, i.e., the effect after about 5-10 years, of rent control on the supply of rental housing? Will rent control increase, keep the same or decrease the number of apartments in the housing market?

o With rent control, more apartments will be offered than without rent control.

o With rent control, approximately the same number of apartments will be offered as without rent control.

o With rent control, fewer apartments are offered than without rent control.

If: more or fewer

By what percentage will the supply of rental housing increase/decrease as a result of the rent control? You can indicate your answer on a scale from $0 \%$ to $100 \%$. 
If: same [Skip to next question]

7. How sure are you about your answer to the previous question? [1-5; very unsure, very sure]

8. What do you think is the medium-term effect, i.e., the effect after about 5-10 years, of rent control on the level of rents? Will rent control cause rents to increase, decrease, or remain unchanged?

o With rent control, rents will be much lower than without rent control.

o With rent control, rents will be lower than without rent control.

o With rent control, rents will be slightly lower than without rent control.

o With rent control, rents will remain roughly the same as without rent control.

o With rent control, rents will be slightly higher than without rent control.

o With rent control, rents will be higher than without rent control.

o With rent control, rents will be much higher than without rent control.

9. How sure are you about your answer to the previous question? [1-5; very unsure, very sure]

10. What do you think is the effect of rent control on the likelihood of existing tenants staying longer in their home, i.e., protecting tenants from being forced to move because of rising rents? [1-10; no effect, very strong effect]

11. If rent control applies, then it could be that the person who values the apartment most does not always get it. How severe do you think this problem is? [1-5; no problem, very severe]

\section{Stated Support Rent Control}

12. How much do you support or oppose rent control policy, i.e. the introduction of a price cap on rents? [1-10; very strongly oppose, very strongly support] 


\section{Additional Attitudes}

13. Do you generally support government interventions such as statutory price ceilings or floors? Note: Price floors are minimum prices set by law, such as minimum prices for agricultural products, rent control or the minimum wage. Price ceilings are maximum prices set by law, such as rent limits. [1-10; very strongly opposed, very strongly support]

14. Politically more right-wing parties traditionally tend to favor a policy of free markets and are thus opposed government intervention such as price controls. Parties on the left, on the other hand, often advocate state intervention in price formation. Thinking of your own economic policy views, where would you rank these views? [1-11; far left, far right]

15. Do you think the average level of rent prices in Germany is a problem? [1-10; no problem at all, very big problem]

16. Do you agree with the following statement: [1-10; strongly disagree, strongly agree] I am afraid that I will not be able to afford my current apartment in the foreseeable future because of rising rents

17. Do you think you would benefit financially from the introduction of a rent control policy? [1-10; 1 - hurt very much ; 5 - no change, 10 - benefit very much]

18. Do you think rent control in Germany is a fair policy? [1-5; unfair, fair]

19. Do you agree with the following statement: [1-10; strongly disagree, strongly agree] The market economy and the free market are a good thing 